\title{
PROPOSTA DE CONSTRUÇÃO DE UM APLICATIVO PARA REALIZAÇÃO DAS ESCALAS DA EQUIPE DE ENFERMAGEM
}

\section{Dielli Arend Teixeira ${ }^{1}$; Adriana Dall Asta $^{2}$; Carla Lizandra de Lima Ferreira ${ }^{3}$; Alessandro Trevisan Monteiro ${ }^{4}$;Regina Gema Santini Costenaro ${ }^{5}$.}

\section{RESUMO}

Objetivou-se, desenvolver uma tecnologia, do tipo aplicativo, para a realização das escalas do serviço da equipe de enfermagem. Metodologia: Trata-se de um estudo de caráter metodológico, diante ao desenvolvimento de um aplicativo, para realizar as escalas mensais dos profissionais da equipe de enfermagem. Para desenvolver este aplicativo, foi necessário construir uma parceria com alunos e professor da área de tecnologia de informação. Resultados e discussão: Foi desenvolvido com os profissionais da Tecnologia de informação, o aplicativo intitulado "app escala", disponivel para androide. Conclusão: Dada a problemática da questão, conclui-se a importância de um olhar minucioso as demandas que se encontram no ambiente de serviço. O planejamento final do aplicativo é surgir uma tela onde possa ser posto apenas os nomes dos profissionais e turno e este automaticamente realizaria a escala, porem este requer demanda mais alta de tempo para ser desenvolvido, e os profissionais não iriam conseguir realizá-lo no prazo estipulado.

\footnotetext{
${ }^{1}$ Graduanda do curso de enfermagem e bolsista PROBIC da Universidade Franciscana-UFN, Santa Maria, RS. Membro do GIPES. E-mail: dielliarend@gmail.com

${ }^{2}$ Enfermeira. Doutora em Ciências. Professora adjunta da Universidade Franciscana, Santa Maria, RS. E-mail: adrianadallasta@ufn.edu.br

${ }^{3}$ Enfermeira. Doutora em Ciências. Coordenadora do Curso de Enfermagem e Professora Assistente da Universidade Franciscana - UFN. Santa Maria RS. Email: carlafer@ufn.edu.br 4 Enfermeiro. Nutricionista. Mestre em saúde materno infantil UFN. Docente do Instituto federal de edicação Tocantins- Tocantins. TO. Email: alessandro_atm@hotmail.com

5 Enfermeira. Doutora em Ciências. Professora adjunta da Universidade Franciscana, Santa Maria, RS, BR. E-mail: reginacostenaro@gmail.com
} 
Palavras-chave: Enfermagem; Inovação; Promoção da saúde.

\section{Eixo Temático: Atenção Integral e Promoção à Saúde - AIPS}

\section{INTRODUÇÃO}

O enfermeiro como gestor de sua equipe, tem como principal função adequar - serviço de saúde nas necessidades/fragilidades do seu local de atuação. Identificando isso, intervém também com novas tecnologias de saúde entre sua equipe, aprimorando o serviço, e readequando a fatores externos e internos, utilizando também a tecnologia em sua tomada de decisão (PISSAIA et al., 2018).

Ao pensar sobre as potencialidades da utilização da tecnologia no serviço de saúde, além da melhoria na tomada de decisão. É fundamental observar que o enfermeiro é direcionado a trabalhos burocráticos, onde este envolve tempo, ao relacionar com melhorias e implementação de tecnologias, nota-se que se fosse realizado por papeis, o tempo do enfermeiro seria mais escasso do que é atualmente com estas formas de trabalhar (MACHADO et al., 2019).

Além da grande valia da comunicação do enfermeiro com sua equipe, tornase indispensável a realização da comunicação entre profissionais da informática. Onde estes podem estar ativamente inserido nos serviços de saúde, a fim de aprimorar os recursos utilizados nesta área. O profissional identificando possíveis melhorias na atuação entre serviço e usuário, pode informar a estes profissionais, a fim de realizar melhorias ativas no contexto de saúde (MACHADO et al., 2019).

O Ministério da Saúde, no desenvolvimento de maiores estratégias para a organização do trabalho dos gestores de saúde, cria o Sistema de Informação em Saúde (SIS). Entre uma das funções desta estratégia é a verificação das condutas e manejo de cada município, resultando em seus percentuais a fim de obter a média de seus resultados, e não necessariamente existir apenas um local para ser informado estes dados. O município fica apto a realizar a partir do SIS a suas condutas para melhor manejo de seus problemas dentro do município, fazendo a 
média da necessidade, e provendo ações estratégicas para melhor resolvê-los (RODRIGUES et al., 2019).

Entre as estratégias do funcionamento do trabalho entre os profissionais de saúde, enfatiza-se a falta de profissionais qualificados, carga horaria excessiva, resultando a evasão destes para países desenvolvidos em busca de melhores condições de trabalho. Ainda é percebido a fragilidade sobre o dimensionamento do pessoal dentro dos serviços de saúde, porém com novas dinâmicas de serviço, e avanços na pesquisa, é previsto a diminuição desta fragilidade, para que assim se customize o tempo e os recursos envolvidos no processo de cuidado. (de MAGALHÃES, RIBOLDI, DALL'AGNO, 2009).

Justifica-se este tema pelo dato de que os recursos humanos no trabalho de enfermagem, deve ser calculado de maneira a atender a legislação e as diretrizes do Conselho Federal de Enfermagem-COFEn. A Resolução COFEN 293/2001 revogada pela resolução 543/2017 fixa e estabelece parâmetros para o dimensionamento do quadro de profissionais de enfermagem nas unidades assistenciais das instituições de saúde e assemelhados.

Este prescreve um cálculo de dimensionamento de pessoal, assim como definir o número de pacientes que podem ficar sob responsabilidade de um técnico de enfermagem e de um enfermeiro de acordo com a complexidade do cuidado, ou seja, define necessidades destes pacientes, quanto a comorbidade e gravidade. Com isso, o enfermeiro deve estar atento à resolução mantendo o quadro de colaboradores e assim auxiliar para a realização da escala de serviço, distribuindo de maneira coesa o número de profissionais nas escalas conforme a complexidade do cuidado para uma assistência com qualidade (BRASIL, 2018).

Além disso, nos indicadores nacionais, o Ministério da Saúde (MS) publicou, em 2018, a Agenda Nacional de Prioridades de Pesquisa em Saúde (APPMS), com foco em diversos assuntos. Dentre estes destaca-se quatro eixos, que se relacionam com a temática proposta nesta pesquisa, quais sejam: eixo 1 - Ambiente, trabalho e saúde; eixo 4 - Desenvolvimento de Tecnologias e Inovação em Saúde; eixo 7 Economia e Gestão em Saúde; eixo 8 - Gestão do Trabalho e Educação em Saúde (BRASIL, 2018). 
Frente ao exposto, a questão norteadora deste estudo foi: um aplicativo tecnológico pode auxiliar na realização das escalas de trabalho da equipe de enfermagem? Assim, objetivou-se, propor uma tecnologia, do tipo aplicativo, para a realização das escalas do serviço da equipe de enfermagem.

\section{METODOLOGIA}

Trata-se de um estudo de caráter metodológico, diante ao desenvolvimento de um aplicativo, para realizar as escalas mensais dos usuários de serviço de saúde. Para desenvolver este aplicativo, foi necessário construir uma parceria com alunos e professor da área de tecnologia de informação, os quais auxiliaram em todas as etapas da construção do aplicativo.

A proposta para desenvolver este aplicativo, foi seguido quatro (4) fases, quais sejam:

Fase 1: Coleta de informações: Etapa que consistiu na busca das informações das fragilidades dos enfermeiros na realização da escala, e os dados necessários para construção da mesma, que deveria conter: Nome dos colaboradores, dias e turnos de trabalho, bem como somar 40 horas semanais de acordo com o contrato de trabalho, da instituição hospitalar.

Fase 2: Coleta de informações na literatura: Foi realizado a busca de artigos científicos que enfatizassem a importância das escalas mensais de trabalho para melhor operacionalização das rotinas e serviços da equipe de enfermagem, e criação de aplicativos na área da saúde.

Fase 3: Análise de requisitos: Realizado a definição das informações necessárias que deveriam conter no aplicativo e após foram apresentados aos alunos da TI para o setor de tecnologia.

Fase 4: Desenvolvimento: Esta fase constituiu cinco (5) encontros com os profissionais da $\mathrm{TI}$, para o desenvolvimento deste aplicativo. No primeiro encontro, foi realizado a apresentação dos colaboradores para o aplicativo, bem como o objetivo deste. No segundo encontro foi realizado a visualização das telas e o andamento. Já no terceiro encontro os profissionais da tecnologia de informação 
mostraram o que pode ser feito até o determinado momento. Assim, o último encontro resultou na presença do coordenador do curso, para falar sobre a sequência do aplicativo, pois o mesmo não estava apresentando na forma final.

Fase 5 implementação: Está fase será realizada posteriormente em acordo com a equipe de gerenciamento do hospital.

\section{RESULTADOS E DISCUSSÕES}

Esta proposta de aplicativo foi desenvolvida com o intuito de auxiliar os profissionais da área de saúde para que haja uma dinâmica mais rápida e fácil, customizando o tempo destes profissionais para a realização destas escalas. Lembrando que a escala pode ser flexível, com o horário da realização dos turnos, nomes dos profissionais, criação de novas unidades e pedidos de trocas. Foi desenvolvido com os profissionais da Tecnologia de Informação o aplicativo. O planejamento final do aplicativo é surgir uma tela onde possa apenas ser colocado os nomes dos profissionais e turno e este automaticamente realizaria a escala.

O nome escolhido para o aplicativo foi "App escala". O primeiro layout que o usuário tem acesso corresponde ao desenho do aplicativo (logomarca), ao acessar este programa, o profissional será encaminhado para o login do aplicativo, onde colocará o nome e a senha, para que haja privacidade nos seus documentos. A partir de então será direcionado para a página principal do aplicativo. Nesta estará representada cinto itens que darão acesso aos menus principais do aplicativo.

Este contém menus para: "Gerenciar usuário" no qual este foi colocado os nomes dos funcionários, com a possível maneira de criar um, alterar, excluir ou observar detalhes. Ao criar um usuário, o profissional tem a opção de colocar o que este é, no aplicativo contém as seguintes opções: "técnico de enfermagem", "enfermeiro", "enfermeiro chefe da unidade", "enfermeiro RT", subdivido entre estes, para que se tenha uma login específicos e acesso a determinadas áreas para quais foram os selecionados.

Ao acessar o menu para "gerenciar unidade", este vai ser representado com um "novo cadastro", "editar unidade" e "deletar a unidade", sendo possível que 


\section{QuFN}

apenas o enfermeiro RT possa autorizar estas funções. Ao acessar o item de "gerenciar escala", as unidades iram aparecer, bem como ao selecionar elas, o profissional poderá colocar o turno, onde este será realizado no acesso "gerenciar turnos", este criado diante ao horário iniciar e horário final do turno do usuário. 0 profissional enfermeiro que esta realizando a escala, ao selecionar estes itens da criação do nome, turno e unidade destes usuários, será encaminhado para um calendário, onde será selecionado os dias em que cada usuário ira trabalhar.

No acesso ao "gerenciamento de trocas", sendo disponibilizado para o enfermeiro RT e para o enfermeiro chefe da unidade, este poderá colocar o nome do profissional, e a titulação deste para realizar a troca. Sendo ocorrida automaticamente na escala mensal.

\section{CONCLUSÃO}

Dada a problemática da questão, conclui-se a importância de um olhar minucioso as demandas que se encontram no ambiente de serviço. Ressaltando que o enfermeiro é o principal gestor de novas mudanças no ambiente em que este trabalha. Este deve além de criar ferramentas de cuidado, quantificar e qualificar seu serviço e saúde. A fim de beneficiar sua equipe e seus usuários.

O saber sobre dimensionamento dos profissionais, interliga aspectos fundamentais na criação da escala mensal. Pois diante dele, pode se haver um planejamento específico para a necessidade do local e de sua equipe, diminuindo sobrecargas de serviço e a falta dos profissionais referente ao número de usuários necessitados.

Esta proposta de aplicativo desenvolvida, com profissionais da TI, possibilitou uma dinâmica de debates entre diferentes áreas. Observando a importância em que se tem diferentes áreas de atuação se interligar para realizar algum projeto. Diante aos debates/encontros realizados virtualmente para discutir como seria este aplicativo, notou-se que este demoraria mais tempo para ser realizado, pois este necessita de uma demanda mais alta de horas para ser desenvolvido, e os profissionais não iriam conseguir realizá-lo. 


\section{QUFN}

\section{REFERÊNCIAS}

Brasil. Agenda de Prioridades de Pesquisa do Ministério da Saúde - APPMS [recurso eletrônico] / Ministério da Saúde, Secretaria de Ciência, Tecnologia e Insumos Estratégicos, Departamento de Ciência e Tecnologia. - Brasília :Ministério da Saúde, 2018.

de MAGALHÃES, A. M.; RIBOLDI, M. C. de O.; Dall'Agnoll, C. M. Planejamento de recursos humanos de enfermagem: desafio para as lideranças. Rev Bras Enferm, v.62, n.4, p. 608-12. 2009.

MACHADO, G. dos R. ÉVORAI, Y. D. M.; RANGEL, A. Leite. SILVEIRA R. C. de C. P. et al., Desenvolvimento de um software para a assistência de enfermagem intraoperatória. Rev Bras Enferm. v.72, n.3, p.714-20, 2019.

PISSAIA, L. F.; da COSTA, A. E. K.; MORESCHI, C.; REMPEL. C.; Impacto de tecnologias na implementação da sistematização da assistência de enfermagem hospitalar: uma revisão integrativa. Rev Epidemiol Control Infec, v.8, n.1, p.92-100, 2018.

RODRIGUES, W.P; MARTINS, F. L.; de CARVALHO, F. L. O.; COSTA, D. de M. et al. Importância do enfermeiro gestor nas instituições de saúde. Revista Saúde em Foco - Edição no 11, p. 382-395. 2019. 